\title{
Transient and continuant authors in robotic medicine: A scientometric view
}

\author{
J. P. S. Kumaravel ${ }^{*}$, P. Pricilla Rani ${ }^{1}$, S. Kalai Selvi ${ }^{2}$ \\ Department of Library and Information Science, DDE, Madurai Kamaraj University, ${ }^{2}$ Senthamil College, Madurai, ${ }^{1}$ Avinashilingam Deemed \\ University for Women, Coimbatore, Tamil Nadu, India
}

\begin{abstract}
The purpose of this study is to conduct a scientometric analysis of the body of literature on robotic medicine covered by PubMed database for a period from 2000-2011 and identify the quantum of transient and continuant authors. A total of 9906 articles were downloaded from PubMed database using the search term robotics in mesh headings subjected to scientometric data analysis techniques. A number of research questions pertaining to publication frequency, country of publication, individual productivity of authors, continuant, and transient nature of authors were proposed and answered. Based on the findings, many implications emerged that improve one's understanding of the identity of robotic medicine as a distinct biomedical field. The pool of articles is drawn from PubMed database only though there are other databases also.
\end{abstract}

Keywords: Robotics medicine, scientometrics, Transient and continuant authors

\section{INTRODUCTION}

Robots play a critical - and growing - role in modern medicine, from training the doctors, dentists, and nurses, to comforting and protecting elderly patients. Using robots, medical professionals can make smaller incisions for shorter surgeries, reducing hospital stays and improving patients' prognoses and saving costs. As robots become even smaller and developers continue to further integrate the devices with artificial intelligence, the medical community will continuously expand the ways in which it uses this technology to save patients, improve the quality-of-life and prevent health problems. At the other end of the spectrum, medical schools are turning to robots that mimic live patients' feelings of pain or discomfort

*Address for correspondence:

E-mail: jpskumar@yahoo.com

\begin{tabular}{|l|l|}
\hline \multicolumn{2}{|c|}{ Access this article online } \\
\hline Quick Response Code: & \\
\hline & Website: \\
\hline
\end{tabular}

to help the next wave of doctors and dentists prepare to treat real people.

Research on robotics for medical applications started 15 years ago and is very active today. The purpose is three-fold. First, it is for robotic surgery. Robotic surgery can accomplish what doctors cannot because of precision and repeatability of robotic systems. Besides, robots are able to operate in a contained space inside the human body. All these make robots especially suitable for noninvasive or minimally invasive surgery and for better outcomes of surgery. Today, robots have been demonstrated or routinely used for heart, brain, spinal cord, throat, and knee surgeries at many hospitals in the United States. For medical applications, Russell Taylor of the Johns Hopkins University summarized core challenges in three areas: Modeling and analysis, interface technologies, and systems, which are described below (Taylor, 2004):

- For modeling and analysis, the emphasis is on developing computationally effective methods for patient specific modeling and analysis

- For interface technology, the emphasis is to fundamentally extend the sensory, motor, and human adaptation abilities of computer-based systems in an unusually demanding and constrained environment 
- For systems, the emphasis is on developing architectures, building blocks and analysis techniques that facilitate rapid development and validation of versatile computer integrated surgery systems and processes with predicable performance.

\section{Related Literature}

"There is no doubt that the U.S. is leading the world in the research of robotics for biological and medical applications. However, other countries are catching up; many organizations in Japan, Korea and Europe actively participating in the research and more of the others are joining". 1

\section{METHODS AND APPROACH}

\section{Approach}

The primary objective of this study was to identify and analyze the global research literature that was related directly to Medical Robotics. Since Scientometrics is an important tool used for studying the structure of literature and productivity of a subject PubMed database was selected as the database. The keyword used for the query was Robotics in Mesh Subheadings and the period of coverage was 1972-2011. The downloaded data in the text format was converted into MS Access database and the total records taken for analysis was 9906 of which the records pertaining to the period from 2001 to 2011 were considered for analysis. The retrieved database consisted of selected journal records (including authors, titles, journals, author addresses, author keywords, and abstract narratives. The discussion described global scientific production on Medical Robotics research from following aspects:

- Growth of global publication output from 2001 to 2011.

- Authorship pattern

- Countries of publication

- Authorship pattern and co-authorship of papers

- Continuant and transient authors.

\section{DISCUSSION}

Medical Robotics research literature takes its origin in the year 1972 and until 1996, the publication is very low $(<100)$. In 1997, the research had gained momentum. An analysis of the publication growth from the new millennium shows

\footnotetext{
${ }^{1}$ Yuan Zheng, George Bekey and Arthur Sanderson. Robotics for biological and medical applications. wtec panel report on international assessment of research and development in robotics. 2006. http://www.wtec.org/robotics/report/screen-robotics-final-reporthighres.pdf

that without any reason, there is the maximum growth in the years 2002 and 2011. The average growth rate works out to $0.02 \%$. This shows that research in Medical Robotics is on the increase [Table 1 and Figure 1].

The pattern of authorship in Medical robotics ranges from solo research to research by 36 scholars. Joint authored publications ranks third while publications by three authors ranks second. When the number of authors decreases less than four, the number of publications decreases. This shows that the optimum number of scholars in team research in the subject Medical robotics is 3-4. The study also establishes the fact that collaborative research is replacing solo research in most of the science subjects [Table 2].

\begin{tabular}{lccc}
\multicolumn{4}{l}{ Table 1: Growth of medical robotics research } \\
\hline Year & Count & Percent & Growth rate \\
\hline Before 1990 & 149 & 1.50 & \\
$1991-2000$ & 1140 & 11.51 & \\
2001 & 262 & 2.64 & \\
2002 & 346 & 3.49 & 0.32 \\
2003 & 439 & 4.43 & 0.27 \\
2004 & 547 & 5.52 & 0.25 \\
2005 & 577 & 5.82 & 0.05 \\
2006 & 682 & 6.88 & 0.18 \\
2007 & 862 & 8.70 & 0.26 \\
2008 & 915 & 9.24 & 0.06 \\
2009 & 1151 & 11.62 & 0.26 \\
2010 & 1227 & 12.39 & 0.07 \\
2011 & 1609 & 16.24 & 0.31 \\
& 9906 & 100.00 & \\
\hline
\end{tabular}

Table 2: Authorship pattern

\begin{tabular}{lccccc}
\hline No. of authors & Count & Percent & No of authors & Count & Percent \\
\hline 0 & 90 & 0.91 & 16 & 13 & 0.13 \\
1 & 1563 & 15.78 & 17 & 1 & 0.01 \\
2 & 1449 & 14.63 & 18 & 5 & 0.05 \\
3 & 1559 & 15.74 & 19 & 2 & 0.02 \\
4 & 1443 & 14.57 & 20 & 5 & 0.05 \\
5 & 1119 & 11.30 & 21 & 1 & 0.01 \\
6 & 940 & 9.49 & 22 & 2 & 0.02 \\
7 & 656 & 6.62 & 23 & 1 & 0.01 \\
8 & 443 & 4.47 & 24 & 7 & 0.07 \\
9 & 246 & 2.48 & 25 & 4 & 0.04 \\
10 & 137 & 1.38 & 26 & 5 & 0.05 \\
11 & 87 & 0.88 & 27 & 1 & 0.01 \\
12 & 56 & 0.57 & 29 & 2 & 0.02 \\
13 & 31 & 0.31 & 30 & 1 & 0.01 \\
14 & 20 & 0.20 & 32 & 1 & 0.01 \\
15 & 15 & 0.15 & 36 & 1 & 0.01 \\
& & & & 9906 & 100.00 \\
\hline
\end{tabular}


Though the author productivity depends upon the total publication count, ranking of authors can be done in three ways namely publication count, weighted share, and weightage according to positional share. The weighted share is obtained by giving equal share to all the authors in publications. For example, in a publication of four authors, the share of each author is 0.25 . The weightage according to positional share can be calculated by giving the weightage according to the position of an author in the named list of authors in a publication. Table 3 shows that the total publication count alone cannot be criteria for ranking the authors. The author Shalhav has published 42 papers and ranks $9^{\text {th }}$ according to total publication count. However, he is in the $123^{\text {rd }}$ place when arranged according to the positional share since his name occurs in the last position in most of his publications [Table 3].

Many of the richest areas for research in the sociology of science depend upon some understanding of what may be called the actuarial statistics of the scientific community. One needs to know the dynamical processes which govern emergence, survival and disappearance within that community. Undoubtedly, the most important phenomenon, hitherto not well-recognized, is that at any given time a large number of those working at the research front are transients whose names have never appeared before and will not appear again in the record. ${ }^{[1]}$ In this study, it is found that the total number of authors who have

Table 3: Ranked authors

\begin{tabular}{lcccc}
\hline Author name & Count & Rank & $\begin{array}{c}\text { Rank } \\
\text { according } \\
\text { to share }\end{array}$ & $\begin{array}{c}\text { Rank according } \\
\text { to positional } \\
\text { weight }\end{array}$ \\
\hline Menon M & 91 & 1 & 1 & 1 \\
Dasgupta P & 66 & 2 & 2 & 2 \\
Krebs HI & 61 & 3 & 6 & 5 \\
Chitwood WR Jr & 53 & 4 & 3 & 6 \\
Hemal AK & 53 & 4 & 4 & 3 \\
Oleynikov D & 50 & 5 & 10 & 15 \\
Gill IS & 48 & 6 & 7 & 12 \\
Patel VR & 48 & 6 & 12 & 11 \\
Hogan N & 46 & 7 & 14 & 20 \\
Tewari A & 44 & 8 & 18 & 18 \\
Dario P & 44 & 8 & 23 & 55 \\
Shalhav AL & 42 & 9 & 30 & 123 \\
Zorn KC & 42 & 9 & 13 & 8 \\
Nifong LW & 42 & 9 & 19 & 13 \\
Reinkensmeyer DJ & 42 & 9 & 11 & 9 \\
Bonatti J & 41 & 10 & 37 & 52 \\
Ahlering TE & 40 & 11 & 9 & 10 \\
Zagaja GP & 39 & 12 & 34 & 80 \\
Kaouk JH & 38 & 13 & 29 & 42 \\
\hline & & & &
\end{tabular}

contributed to research literature on Medical robotics is 23071. Those authors who have contributed for more than 5 years are considered as continuant authors. In 2001, among the 838 contributors, only 8 (nearly $0.95 \%$ ) are continuous in their research productivity. Similarly, in 2007, among the 3031 authors, $134(4.42 \%)$ are continuously publishing in the field of Medical Robotics. This shows that very small percent of the scholars are continuously active in the field of Medical Robotics. That is, transient authors occupy greater percent in the publication productivity [Table 4].

\section{CONCLUSION}

The present investigation has thrown light on the trend of research in Medical Robotics. Though the subject has a growing trend, the growth is not high. This shows that this subject will be stable for more number of years. Furthermore, collaborative research is the trend of the day as revealed by this investigation. The quantum of transient authors shows that more authors are entrants to this field of research.

Robotic technology has successfully produced valuable tools for rehabilitation, surgery, and medical training, as well as new and improved prosthetics and assistive devices for people with disabilities. Research on robotics for

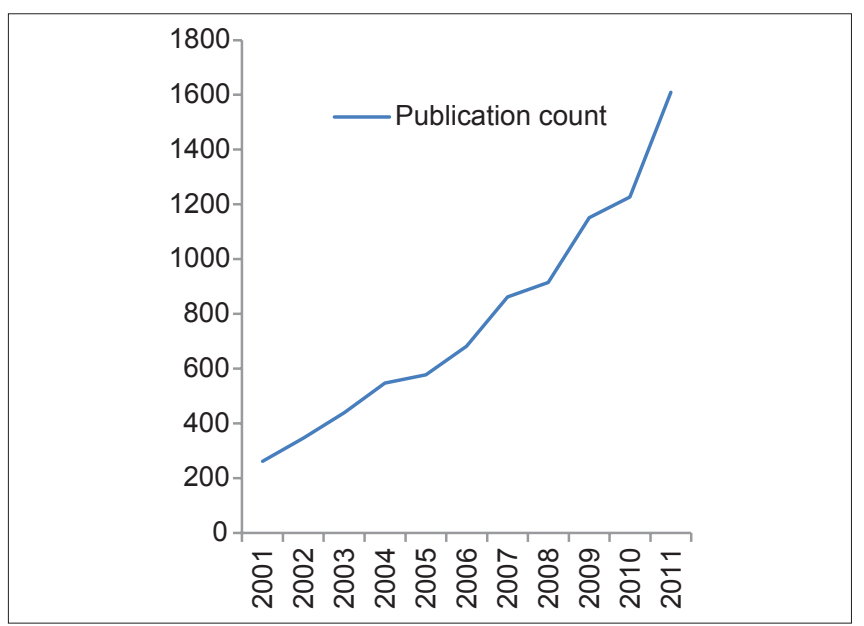

Figure 1: Trend of research in robotic medicine

Table 4: Transient and continuant authors

\begin{tabular}{ccccc} 
Year & $\begin{array}{c}\text { Publication } \\
\text { count }\end{array}$ & $\begin{array}{c}\text { No of } \\
\text { authors }\end{array}$ & $\begin{array}{c}\text { Continuous } \\
\text { authors }\end{array}$ & $\begin{array}{c}\text { Percent of } \\
\text { continuous authors }\end{array}$ \\
\hline 2001 & 262 & 838 & 8 & 0.95 \\
2002 & 346 & 1110 & 9 & 0.81 \\
2003 & 439 & 1512 & 13 & 0.86 \\
2004 & 547 & 1760 & 29 & 1.65 \\
2005 & 577 & 2046 & 49 & 2.39 \\
2006 & 682 & 2329 & 74 & 3.18 \\
2007 & 862 & 3031 & 134 & 4.42 \\
\hline
\end{tabular}


biological and medical applications is still young. Scientists in the U.S. are more active in identifying and developing new applications of robotics for the two applications. Many significant results have been achieved, and some have been commercialized to become useful devices and systems such as the da Vinci surgical system (International Journal of Emerging Medical Technologies, 2005). In the U.S., the number of institutions involved in the research of robotics for both applications is significantly higher than any other country while the quality of research is equally good. It is believed that any new breakthrough in biology and in medicine may need revolutionary tools, perhaps in robotics, to take place. Although, the U.S. is still leading the world in the two applications, more and more countries are participating and making impressive progress. After all, the field has potential to bring great economic impact.

\section{FURTHER READINGS}

1. Hillman M. Rehabilitation robotics from past to present. Proceedings of the Eighth International Conference on Rehabilitation Robotics; April 2003.

2. Available from: http://www.medgadget.com/archives/2005/07/ da_vinci_robot.html.

3. Kumaravel JP, Kanagavel, B, Muthuchidambaram, A and Duraisingam, A( Nanomedical science research performance:
A scientometric view. Nanosci Nanotechnol 2011;5).

4. Bandyopathyah AK. Authorship pattern in different disciplines. Ann Libr Inf Stud Vol. 48 No. 4 p. 139-47.

5. Behrens $\mathrm{H}$, Luksch P. A bibliometric study in crystallography. Acta Crystallogr B 2006;62:993-1001.

6. Bernal JD. The form and distribution of scientific papers. In: The Royal Society Empire Scientific Conference, June-July 1946: Report. London: Royal Society; 1945. p. 698-9.

6. Braun T. World science in the eighties, national performance in publication output and citation impact. Part 1. Science fields combined physics and chemistry. Scientometrics 1994;29:299-334.

8. Cano V. Bibliometric overview of library and information science research in Spain. J Am Soc Inf Sci 1999;50:675-80.

9. Jacobs $D$. A bibliometric study of the publication patterns of scientists in South Africa 1992-96. Inf Res 2001;6:129-37.

10. Gupta BM, Dhawan SM. A scientometric analysis of $S$ and $T$ publications output by India during 1985-2002. Desidoc J Libr Inf Technol 2008;28:73-85.

11. Kumaravel JP. Economic growth, population and research output-A scientometric analysis of genetic engineering $-1988-2000$. Iaslic Bull 2005;50:52-9.

\section{REFERENCE}

1. De La Solla P, Gursey S. Studies in scientometrics: Transience and continuance in scientific authorship. Ciencia da informacio $1975 ; 4: 27-40$.

How to cite this article: Kumaravel J, Rani PP, Selvi SK. Transient and continuant authors in robotic medicine: A scientometric view. J Sci Res 2013;2:202-5.

Source of Support: Nil, Conflict of Interest: None declared

\section{Author Help: Reference checking facility}

The manuscript system (www.journalonweb.com) allows the authors to check and verify the accuracy and style of references. The tool checks the references with PubMed as per a predefined style. Authors are encouraged to use this facility, before submitting articles to the journal.

- The style as well as bibliographic elements should be $100 \%$ accurate, to help get the references verified from the system. Even a single spelling error or addition of issue number/month of publication will lead to an error when verifying the reference.

- $\quad$ Example of a correct style

Sheahan P, O'leary G, Lee G, Fitzgibbon J. Cystic cervical metastases: Incidence and diagnosis using fine needle aspiration biopsy. Otolaryngol Head Neck Surg 2002;127:294-8.

- Only the references from journals indexed in PubMed will be checked.

- $\quad$ Enter each reference in new line, without a serial number.

- $\quad$ Add up to a maximum of 15 references at a time.

- If the reference is correct for its bibliographic elements and punctuations, it will be shown as CORRECT and a link to the correct article in PubMed will be given.

- If any of the bibliographic elements are missing, incorrect or extra (such as issue number), it will be shown as INCORRECT and link to possible articles in PubMed will be given. 